\title{
Análise de Modos e Efeitos de Falha na avaliação dos impactos ambientais provenientes do abate animal
}

\author{
Failure Mode and Effect Analysis for the evaluation of environmental \\ impacts of animal slaughter
}

Mariane Helena Sances Rabelo', Eric Keven Silva', Alexandre de Paula Peres²

口-

\begin{abstract}
RESUMO
A Análise de Modos e Efeitos de Falha (AMEF) é um método de análise de produto ou processo para detectar e eliminar problemas potenciais de forma sistemática e completa. Os abatedouros levam a significativos impactos sobre o meio ambiente, sendo que o maior problema nesses processos é a falta de equipamentos modernos para promover a remoção de gases fétidos e efluentes tóxicos. O objetivo deste trabalho foi elaborar os formulários de aplicação do FMEA em um frigorífico de médio porte da região de Poços de Caldas (MG), o qual realiza abates de bovinos e suínos, cujo intuito foi diagnosticar os potenciais riscos gerados pelo frigorífico, e aos controles ambientais exercidos em relação à linha de abate e graxaria. Observou-se que a indústria frigorífica representa um grande potencial poluidor sobre os efluentes naturais, pois o sangue resultante do abate é um agente de grande impacto sobre o ecossistema hídrico.

Palavras-chave: abate de bovino; abate de suíno; controle de poluição; águas residuárias.
\end{abstract}

\begin{abstract}
The Failure Mode and Effect Analysis (FMEA) is a method of product or process analysis to detect and eliminate potential problems in a systematic and complete way. The abattoirs lead to significant impacts on the environment, which the major problem in those processes is the lack of modern equipment to promote the removal of malodorous gases and toxic effluents. The aim of this study was to elaborate the FMEA application forms in a medium-sized abattoir in the region of Poços de Caldas (MG), which performs the cattle and pig slaughter, with the purpose of diagnosing its potential risks caused, and the environmental controls exercised in relation to the slaughter line and rendering plant. It was observed that the meat industry represents a great potential pollution on the natural effluents, because the resulting blood of the slaughter is an agent of great impact on the water ecosystem.
\end{abstract}

Keywords: cattle slaughter; pig slaughter; pollution control; wastewater.

\section{INTRODUÇÃO}

Conforme descrito por Puente et al. (2001), por volta de 1963, durante a missão Apollo, a NASA desenvolveu um método para identificar de forma sistemática falhas potenciais em sistemas, processos ou serviços antes que estas ocorram. Desta forma, surge o conceito da Análise de Modos e Efeitos de Falha (em inglês, Failure Mode and Effect Analysis, FMEA).

O FMEA é um método de análise de produto ou processo utilizado para identificar todos os possíveis modos potenciais de falha e determinar o efeito de cada um sobre o desempenho do sistema (produto ou processo), mediante um raciocínio basicamente dedutivo (não exige cálculos sofisticados). É, portanto, um método analítico padronizado para detectar e eliminar problemas potenciais de forma sistemática e completa (STAMATIS, 2003).

Segundo Palady (1997) e Stamatis (2003), as principais vantagens da utilização do método FMEA estão relacionadas com melhorias da qualidade, confiabilidade e segurança de produtos ou serviços, e na imagem e competitividade da empresa frente aos seus clientes e a satisfação destes; auxílio na escolha de alternativas de projetos que

'Acadêmica de graduação em Engenharia de Alimentos da Universidade Federal de Lavras (UFLA) - Lavras (MG), Brasil.

2Doutor em Engenharia Química da Universidade Estadual de Campinas (UNICAMP) - Campinas (SP), Brasil. Professor Adjunto do Departamento de Ciência dos Alimentos da UFLA - Lavras (MG), Brasil.

Endereço para correspondência: Mariane Helena Sances Rabelo - Universidade Federal de Lavras - Campus Universitário - Departamento de Ciência dos Alimentos - Caixa Postal 3037 - 37200-000 - Lavras (MG), Brasil - E-mail: marianerabelo1@hotmail.com

Recebido: 05/03/12 - Aceito: 11/10/13 - Reg. ABES: 256 
tenham melhor qualidade, confiabilidade e segurança, assim promovendo a redução de tempo e custo de desenvolvimento na identificação de procedimentos de diagnóstico de falhas para identificar características críticas, significantes e de prevenção de falhas; além de prover a base para programas de testes e validação durante o desenvolvimento de sistemas, produtos, processos ou serviços, documentação histórica para referências futuras, auxiliando análises de futuras falhas e um fórum para recomendação de ações de redução de riscos.

O método FMEA tem sido aplicado como auxílio para definir e priorizar ações corretivas de um projeto, identificação de características críticas e significativas e estabelecimento de um formulário de prevenção de falhas.

Em um levantamento feito pela Comissão Mundial sobre o Meio Ambiente e Desenvolvimento a respeito da poluição industrial, pôde-se constatar que as indústrias químicas de papel e celulose, de ferro e aço, de metais, de geração de eletricidade, de automóveis e de produtos alimentícios encontram-se entre os principais poluidores (DONAIRE, 1999).

No ramo da indústria alimentícia, Moura (2000) destaca a área de laticínios como uma das mais poluidoras, pois há pouco tratamento dos seus efluentes, líquidos que apresentam elevada carga orgânica. Os abatedouros também têm significativos impactos sobre o meio ambiente. Conforme Ferroli et al. (1998), os subprodutos e dejetos originados nesse tipo de indústria podem ser utilizados na produção de farinha e óleo de subprodutos de origem animal (graxarias) e o maior problema decorrente dessas fábricas é a falta de equipamentos modernos para promover a remoção de gases fétidos e efluentes tóxicos.

Além disso, muitas vezes a água de lavagem dos equipamentos, contendo uma série de resíduos, é lançada diretamente no sistema de esgoto. O consumo elevado de água é outro grande problema enfrentado pela indústria alimentícia.

Para avaliar os impactos ambientais provenientes da indústria alimentícia, empregando o método FMEA, destacam-se os trabalhos de Zambrano e Martins (2007), que estudaram uma empresa de fabricação de suco de laranja e óleos essenciais, o de Nogueira et al. (2011), cuja aplicação foi em um laticínio e o de Ozilgen (2012), na fabricação de doces, comprovando que o FMEA pode ser uma referência para as empresas no diagnóstico de riscos ambientais.

Desde as origens do homem a carne faz parte da sua alimentação, sendo essencial por se tratar de uma excelente fonte de proteínas, quer seja um produto de origem bovina, suína ou avícola. $\mathrm{O}$ abate de animais vem aprimorando suas técnicas através dos tempos, proporcionando produtos cada vez mais de melhor qualidade, gerando, entretanto, águas residuárias e uma diversidade de subprodutos.

O objetivo deste trabalho foi elaborar os formulários de aplicação do FMEA de um frigorífico de médio porte da região de Poços de Caldas (MG), o qual realiza abate de bovino e suíno, com o intuito de diagnosticar os potenciais riscos gerados pelo frigorífico e os controles ambientais exercidos em relação à linha de abate e graxaria.

\section{METODOLOGIA}

A forma de apresentação da ferramenta FMEA é no formato de formulários físicos ou digitais. Nesses formulários reúnem-se todas as informações relevantes da ferramenta para facilitar no seu desenvolvimento, análise e interpretação (AGQ, 2006). As matrizes de aplicação do FMEA foram elaboradas de acordo com Zambrano e Martins (2007).

Foram realizadas visitas ao frigorífico para o levantamento das entradas e saídas de cada operação do processo. Para tal levantamento, foi seguido um roteiro de perguntas, previamente estabelecido e estudado de acordo com o fluxograma dos processos de abate de bovinos e suínos, como segue representado nas Figuras 1 e 2, respectivamente, e com base no formulário do FMEA (Quadro 1).

O roteiro foi respondido por funcionários de níveis gerenciais e operacionais, dentre estes: funcionários responsáveis pelo transporte e recepção dos animais no abatedouro, funcionários que operam diretamente na linha de abate e produção, funcionários que operam no setor de graxaria, auxiliares de limpeza e serviços gerais, gerente de produção e o médico veterinário responsável pelo Serviço de Inspeção Federal (SIF) de qualidade sanitária e tecnológica do estabelecimento, contabilizando um total de 97 questionários respondidos.

Após a visita, as respectivas respostas foram padronizadas e registradas pelos aplicadores do roteiro e o formulário do FMEA foi preenchido de acordo com as informações levantadas no roteiro de perguntas.

De acordo com Zambrano e Martins (2007), as colunas desse formulário foram preenchidas da seguinte forma:

- descrição das saídas - função: foram descritas as saídas e a sua função durante o processo produtivo;

- tipo de impacto ambiental: os impactos ambientais que ocorrem cotidianamente na empresa estudada foram classificados como "real"; por outro lado, os impactos que possam vir a ocorrer foram classificados como "potencial";

- efeito do impacto ambiental: descrevem-se os meios envolvidos com o impacto ambiental, estes podem ser: a água, o solo e o ar;

- causa do impacto ambiental: na maioria das vezes, a causa do impacto ambiental é o descarte incorreto dos resíduos e efluentes industriais;

- controles atuais: são as atitudes que a empresa pesquisada adota para impedir que ocorra o impacto ambiental. Quando a empresa não adota nenhuma atitude para mitigar o impacto, essa coluna estará em branco;

- as colunas "S”, “O”, “D”, “A” e "R" representam a "severidade", a "ocorrência", a "detecção", a "abrangência do impacto" e o "risco ambiental";

- a coluna "R", que representa o risco ambiental, é obtida pela multiplicação das colunas "S", "O", "D” e "A". 


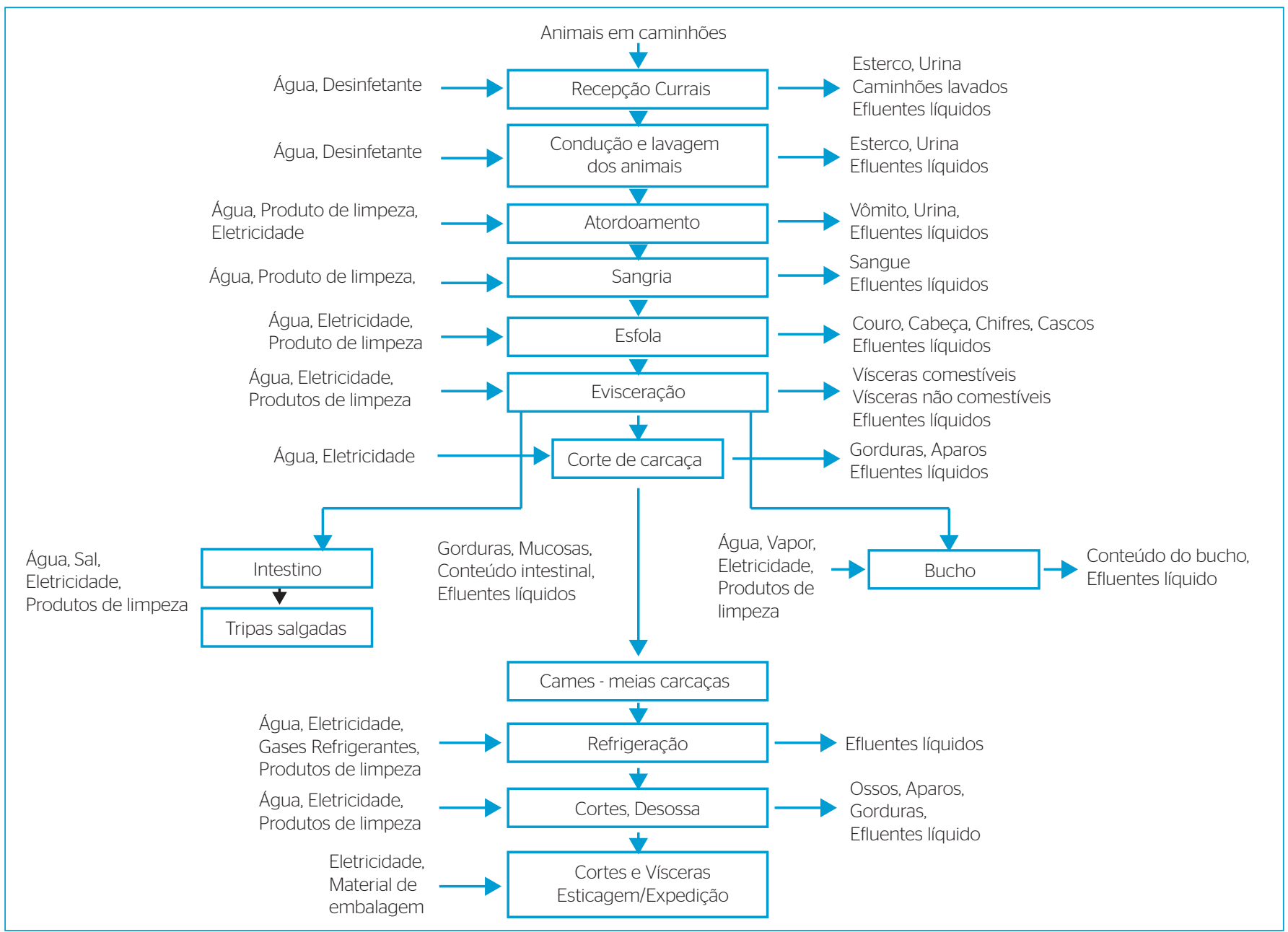

Figura 1 - Fluxograma do abate de bovinos.

- controles ambientais - ações recomendadas: nessa coluna estão descritas as ações que as organizações deveriam adotar para mitigar os impactos ambientais. Quando os "controles atuais" da organização forem julgados como eficazes para mitigar os impactos ambientais, não será recomendada nenhuma ação.

Ao se realizar a análise de riscos ambientais por intermédio do FMEA, foi necessário efetuar algumas adaptações nos índices de severidade, ocorrência e detecção do impacto ambiental, e também foi acrescentado o índice de abrangência do impacto. Nos Quadros 2 a 5 estão descritos os índices adotados. Definiu-se o índice de ocorrência igual a 1 para os impactos ambientais potenciais.

Foram analisadas as seguintes saídas: consumo de água, consumo e armazenamento da lenha, água proveniente da higienização de pisos, equipamentos e carcaças, água proveniente da higienização de currais, pocilgas, corredores, caminhões e animais, fumaça da caldeira, gases provenientes dos digestores, cinzas, sujeiras do chão da fábrica, embalagens de matérias-primas, insumos, embalagens de papel e plástico.
No que diz respeito à saída "Consumo de Água", temos como legislação vigente o Decreto Federal no 24.643 de 10 de julho de 1934, conhecido como Código de Águas, o qual regula o uso dos recursos hídricos, a fim de se evitar o desperdício de água e zelar pela conservação dos mananciais brasileiros. O referido decreto já previa a cobrança pelo uso da água conforme a carga poluidora e contemplava vários princípios estabelecidos na Lei $n^{\circ} 9.433$ de 08 de janeiro de 1997, que instituiu a Política Nacional de Recursos Hídricos e definiu a estrutura jurídico-administrativa do Sistema Nacional de Recursos Hídricos, a Lei n 9.984, 17 de julho de 2000, que criou a Agência Nacional de Águas (ANA) e a Resolução no 16 do Conselho Nacional de Recursos Hídricos, de 08 maio de 2001, que estabeleceu critérios gerais para a outorga de direito de uso de recursos hídricos.

Para as saídas "Água proveniente da higienização de pisos equipamentos e carcaças" e "Água proveniente da higienização de currais, pocilgas, corredores, caminhões e animais", a legislação vigente é a Resolução n ${ }^{\circ}$ 430 de 13 de maio de 2011, do Conselho Nacional do Meio Ambiente (CONAMA), que dispõe sobre a classificação e diretrizes ambientais 
Água, Sal, Eletricidade Produtos de limpeza

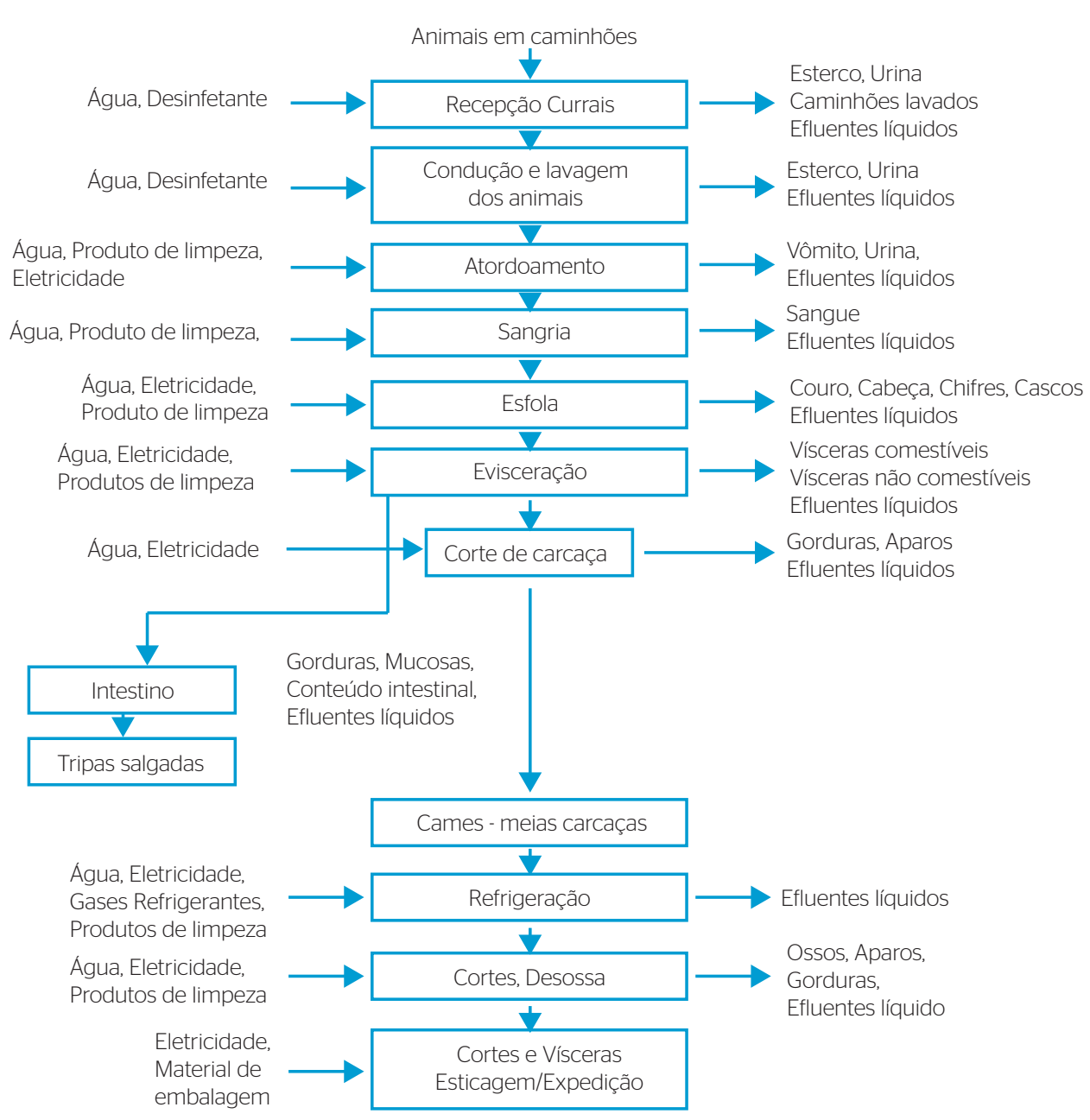

Figura 2 - Fluxograma do abate de suínos.

Quadro 1 - Formulário da Análise de Modos e Efeitos de Falhas.

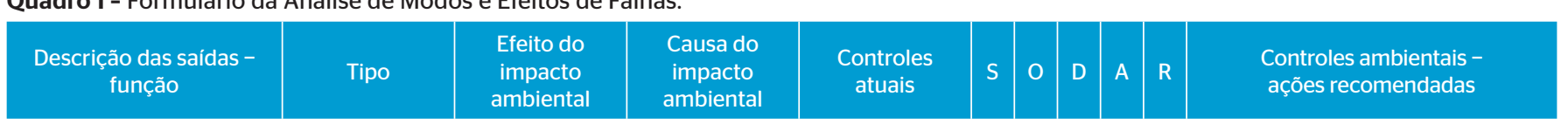

Fonte: Adaptado de Helman e Andrey (1995).

para o enquadramento dos corpos de água superficiais, bem como estabelece as condições e os padrões para o lançamento de efluentes.

\section{RESULTADOS E DISCUSSÃO}

Para o procedimento da pesquisa foi realizado um estudo de caso. A empresa estudada se caracteriza pelo abate de bovinos e suínos e produção de cortes, embutidos, defumados, shark, farinha de sangue, farinha de osso e vísceras não comestíveis e vísceras comestíveis. Localiza-se na região do município de Poços de Caldas (MG), em funcionamento há mais de 50 anos, com cerca de 290 funcionários.
O estudo de levantamento de risco ambiental foi realizado na linha de abate de bovinos e suínos e na graxaria do frigorífico. As Figuras 1 e 2 representam o fluxograma de abate para bovinos e suínos, respectivamente.

Os subprodutos originados para obtenção de carne e derivados devem sofrer processamentos específicos: couros, sangue, ossos, gorduras, aparas de carne, tripas, animais, ou suas partes condenadas pela inspeção sanitária etc.

A finalidade do processamento e/ou da destinação dos resíduos ou dos subprodutos do abate é em função de características locais ou regionais, de acordo com a cultura, costumes e preceitos religiosos. Um exemplo da utilização de subproduto é o sangue 
Quadro 2 - Classificação de severidade.

\begin{tabular}{|l|l|c|}
\hline \multirow{3}{*}{ Alta } & Severidade do Impacto ambiental & Classificação \\
\hline \multirow{3}{*}{ Moderada } & $\begin{array}{l}\text { Produtos muito danosos ao meio ambiente } \\
\text { que apresentam as características: corrosi- } \\
\text { vidade, reatividade, explosividade, toxidade, } \\
\text { inflamabilidade e patogenicidade. }\end{array}$ & 3 \\
& $\begin{array}{l}\text { Produtos danosos ao meio ambiente que } \\
\text { possuem longo tempo de decomposição, } \\
\text { por exemplo: metais, vidros e plásticos. } \\
\text { Também é considerada a utilização de } \\
\text { recursos naturais. }\end{array}$ & 2 \\
\hline Baixa & $\begin{array}{l}\text { Produtos pouco danosos ao meio ambiente } \\
\text { que possuem curto tempo de decomposi- } \\
\text { ção, como papelão e tecidos. }\end{array}$ & \\
\hline
\end{tabular}

Quadro 3 - Classificação de ocorrência de impactos ambientais reais.

\begin{tabular}{|l|l|c|}
\hline Alta & Ocorrência do impacto ambiental & Classificação \\
\hline Moderada & O impacto ambiental ocorre diariamente & 3 \\
\hline Baixa & $\begin{array}{l}\text { O impacto ambiental ocorre semestralmen- } \\
\text { te ou anualmente }\end{array}$ & 1 \\
\hline
\end{tabular}

Quadro 4 - Classificação de detecção.

\begin{tabular}{|l|l|c|}
\hline Alta & $\begin{array}{l}\text { Detecção do impacto ambiental } \\
\text { Para detecção do impacto ambiental é } \\
\text { necessária a utilização de tecnologias } \\
\text { sofisticadas }\end{array}$ & 3 \\
\hline Moderada & $\begin{array}{l}\text { O impacto ambiental é percebido com a } \\
\text { utilização de medidores simples }\end{array}$ & 2 \\
\hline Baixa & $\begin{array}{l}\text { O impacto ambiental pode ser percebido } \\
\text { visualmente }\end{array}$ & 1 \\
\hline
\end{tabular}

Quadro 5 - Classificação da abrangência de impactos ambientais.

\begin{tabular}{|l|c|}
\hline Abrangência do impacto ambiental & Classificação \\
\hline $\begin{array}{l}\text { O impacto ambiental ocorre fora dos } \\
\text { limites da organização }\end{array}$ & 3 \\
\hline $\begin{array}{l}\text { O impacto ambiental ocorre dentro dos } \\
\text { limites da organização }\end{array}$ & 2 \\
\hline $\begin{array}{l}\text { O impacto ambiental ocorre no local onde } \\
\text { está sendo realizada a operação }\end{array}$ & 1 \\
\hline
\end{tabular}

que pode ser processado, visando a separação e o uso, ou comercialização, de seus componentes (plasma, albumina, fibrina etc.), mas também pode ser enviado para as graxarias, para a produção de farinha de sangue, usada normalmente na preparação de rações animais e adubos.

Da mesma forma, os demais subprodutos e/ou resíduos são processados para a produção de diversos produtos cárneos ou destinados à graxaria para o aproveitamento de diversas formas, ressaltando que processamentos e destinações adequadas devem ser dados a todos os subprodutos e resíduos do abate em atendimento às leis e normas vigentes, sanitárias e ambientais.
De acordo com Cikoski (2008), o tratamento de efluentes é uma das mais importantes questões ambientais no que diz respeito ao atendimento da legislação e à consequente proteção ao meio ambiente. Apesar de evoluindo, o setor de tratamento de efluentes no Brasil ainda deixa muito a desejar, devido à carência de recursos para investimentos e às políticas oficiais de inovação tecnológica, as quais parecem não considerar a realidade das micro e pequenas empresas brasileiras.

Nos abatedouros a água é de grande utilidade, sendo altamente consumida na atividade de resfriamento das carcaças. A média de água utilizada por cabeça corresponde de 25 a $50 \mathrm{~L}$. A quantidade de efluente que é produzido é quase que equivalente ao volume de água que é consumida, pois está presente na composição de alguns produtos, como também pode ser absorvida pela carcaça durante o período de resfriamento.

De 60 a 70\% da água que é empregada nos frigoríficos entram em contato direto com produtos cárneos, o restante é usado para fins sanitários em geral (PELISSER; SOARES, 2001 e SENA, 2005). Os frigoríficos que passam pela inspeção do Ministério da Agricultura fazem o tratamento total de seus efluentes, sejam estes sólidos, líquidos ou até mesmo gasosos.

De acordo com o Quadro 6, pode-se observar que a severidade dos impactos na sua maioria obteve índice moderado, impactos danosos ao meio ambiente que possuem longo tempo de duração e é considerada a utilização de recursos naturais, este fator é preocupante, principalmente no quesito que diz respeito aos recursos naturais, estes não renováveis e de extrema importância para o funcionamento de uma unidade frigorífica, recursos tais como a água e os geradores de energia elétrica. A ocorrência deste impacto é diária, devido às intensas atividades dessa unidade produtiva, então tem-se a necessidade de um rigoroso gerenciamento e modificações na estrutura da unidade.

A deteç̧ão dos impactos obteve na sua maioria índice médio, que corresponde à utilização de medidores simples, o que favorece o trabalho, pois sua detecção pode ocorrer com equipamentos simples, que não possuem alto custo e são de fácil manuseio, proporcionando assim uma facilidade em diagnosticar a situação e a gravidade dos impactos.

Os impactos causados têm na sua maioria abrangência nos limiares da organização, já os de abrangência externa são bastante preocupantes, pois atingem áreas de matas, onde se deve lutar para que não ocorra maior degradação ambiental do que a atual.

A água é um bem de grande importância em uma unidade frigorífica e é empregada em quase todas as fases do processo de abate, desossa e produtivo, porém o efluente gerado na unidade é um enorme fator de impacto quando não tratado ou tratado inadequadamente, devendo-se dar particular importância aos valores de Demanda Bioquímica de Oxigênio (DBO) e de Demanda Química de Oxigênio (DQO), como demonstrado por Thebaldi et al. (2011). 
Quadro 6 - Formulário da Análise de Modos e Efeitos de Falha aplicado ao abate bovino e suíno.

\begin{tabular}{|c|c|c|c|c|c|c|c|c|c|c|}
\hline $\begin{array}{l}\text { Descrição das } \\
\text { saídas - Funções }\end{array}$ & Tipo & $\begin{array}{l}\text { Efeito do impacto } \\
\text { ambiental }\end{array}$ & $\begin{array}{l}\text { Causa do impacto } \\
\text { ambiental }\end{array}$ & $\begin{array}{l}\text { Controles } \\
\text { atuais }\end{array}$ & S & 0 & D & A & $\mathrm{R}$ & $\begin{array}{l}\text { Controles ambientais - } \\
\text { ações recomendadas }\end{array}$ \\
\hline Consumo de água & $\mathrm{R}$ & $\begin{array}{l}\text { Utilização dos } \\
\text { recursos naturais }\end{array}$ & $\begin{array}{l}\text { Utilização de água } \\
\text { no processo }\end{array}$ & - & 2 & 3 & 2 & 2 & 24 & $\begin{array}{l}\text { Buscar estratégias para minimizar o } \\
\text { consumo otimizando processos. } \\
\text { Tratamento da água para reutilização. }\end{array}$ \\
\hline $\begin{array}{l}\text { Consumo e } \\
\text { armazenamento } \\
\text { da lenha }\end{array}$ & $\mathrm{R}$ & $\begin{array}{l}\text { Utilização dos } \\
\text { recursos naturais }\end{array}$ & $\begin{array}{l}\text { A lenha é utilizada } \\
\text { para alimentar a } \\
\text { caldeira }\end{array}$ & $\begin{array}{l}\text { Lenha pro- } \\
\text { veniente de } \\
\text { construções } \\
\quad \text { civis }\end{array}$ & 2 & 3 & 1 & 3 & 18 & $\begin{array}{c}\text { Construção de um local para } \\
\text { armazenamento adequado da lenha } \\
\text { (local abrigado, não permitindo ser } \\
\text { molhada) }\end{array}$ \\
\hline $\begin{array}{l}\text { Água proveniente } \\
\text { da higienização de } \\
\text { pisos, } \\
\text { equipamento e } \\
\text { carcaças. }\end{array}$ & $\mathrm{R}$ & $\begin{array}{l}\text { Contaminação da } \\
\text { água }\end{array}$ & $\begin{array}{l}\text { Descarte em } \\
\text { lagoas próximas ao } \\
\text { local de } \\
\text { processamento. }\end{array}$ & $\begin{array}{l}\text { Lagoas } \\
\text { anaeróbias }\end{array}$ & 3 & 3 & 2 & 2 & 36 & $\begin{array}{l}\text { Destinar às lagoas anaeróbias em segui- } \\
\text { da encaminhar para lagoas de floculação }\end{array}$ \\
\hline $\begin{array}{l}\text { Água proveniente } \\
\text { da higienização de } \\
\text { currais, pocilgas, } \\
\text { corredores, cami- } \\
\text { nhões e animais. }\end{array}$ & $\mathrm{R}$ & $\begin{array}{c}\text { Contaminação da } \\
\text { água }\end{array}$ & $\begin{array}{l}\text { Descarte em } \\
\text { lagoas próximas ao } \\
\text { local de processa- } \\
\text { mento }\end{array}$ & $\begin{array}{l}\text { Lagoas } \\
\text { anaeróbias }\end{array}$ & 3 & 3 & 2 & 2 & 36 & $\begin{array}{l}\text { Destinar às lagoas anaeróbias em segui- } \\
\text { da encaminhar para lagoas de floculação }\end{array}$ \\
\hline Fumaça da caldeira & $\mathrm{R}$ & $\begin{array}{l}\text { Contaminação } \\
\text { do ar }\end{array}$ & $\begin{array}{l}\text { Descarte na } \\
\text { atmosfera }\end{array}$ & $\begin{array}{l}\text { Filtros nas } \\
\text { chaminés }\end{array}$ & 2 & 3 & 2 & 2 & 24 & $\begin{array}{c}\text { Manutenção periódica nos filtros e } \\
\text { caldeiras, troca do equipamento } \\
\text { quando necessário. }\end{array}$ \\
\hline $\begin{array}{l}\text { Gases provenien- } \\
\text { tes dos digestores }\end{array}$ & $\mathrm{R}$ & $\begin{array}{l}\text { Contaminação } \\
\text { do ar }\end{array}$ & $\begin{array}{l}\text { Descarte na } \\
\text { atmosfera }\end{array}$ & - & 2 & 3 & 2 & 2 & 24 & Instalação e manutenção de filtros \\
\hline Cinzas & $\mathrm{R}$ & $\begin{array}{l}\text { Contaminação da } \\
\text { água }\end{array}$ & $\begin{array}{l}\text { Proveniente da } \\
\text { queima na caldeira }\end{array}$ & - & 2 & 3 & 2 & 2 & 24 & Aplicação em local adequado. \\
\hline $\begin{array}{l}\text { Sujeira do chão da } \\
\text { fábrica }\end{array}$ & $\mathrm{R}$ & $\begin{array}{l}\text { Contaminação do } \\
\text { solo e da água }\end{array}$ & $\begin{array}{c}\text { Parte da sujeira é } \\
\text { encaminhada para } \\
\text { a graxaria e a outra } \\
\text { é carreada pela } \\
\text { água de lavagens } \\
\text { do frigorífico. }\end{array}$ & - & 3 & 2 & 2 & 2 & 24 & $\begin{array}{c}\text { Triagem com maior critério das } \\
\text { sujeiras e filtros de retenção na saída de } \\
\text { efluentes. }\end{array}$ \\
\hline $\begin{array}{l}\text { Embalagens de } \\
\text { matérias -primas, } \\
\text { insumos, } \\
\text { embalagens de } \\
\text { papel e plástico }\end{array}$ & $\mathrm{R}$ & $\begin{array}{l}\text { Contaminação do } \\
\text { solo }\end{array}$ & $\begin{array}{l}\text { As embalagens são } \\
\text { encaminhadas à } \\
\text { empresa coletora } \\
\text { de lixo }\end{array}$ & - & 2 & 3 & 1 & 3 & 18 & $\begin{array}{l}\text { Separação das embalagens e } \\
\text { encaminhamento para a reciclagem }\end{array}$ \\
\hline
\end{tabular}

A saída "Consumo de água" obteve severidade Moderada, que corresponde à utilização de recursos naturais, sendo assim um fator de grande preocupação, já que este é um recurso não renovável e de essencial importância à sobrevivência humana. A ocorrência desse evento obteve classificação Alta, o que implica em um uso do recurso diariamente, tornando assim essa saída mais agravante. Desta forma, a unidade frigorífica deve buscar aperfeiçoar seus processos, de forma a minimizar a utilização desse recurso natural sem perda da eficiência produtiva.

Tão importante quanto reduzir o consumo, é tratar o efluente remanescente e reutilizá-lo. Por tal motivo, as saídas "Água proveniente da higienização de pisos, equipamento e carcaças" e "Água proveniente da higienização de currais, pocilgas, corredores, caminhões e animais" obtiveram classificação Alta para ocorrência e severidade, o que corresponde aos eventos de ocorrência diária e produtos muito danosos ao meio ambiente, os quais apresentam as características patogenicidade e toxidade, que se não tratados, ou tratados de forma inadequada, podem causar danos ao meio ambiente, e em consequência podem levar a danos para a saúde humana.

No frigorífico avaliado neste trabalho, constatou-se que todos os efluentes líquidos são destinados às lagoas anaeróbias. De acordo com Scarassati (2003), a eficiência de remoção de DBO nas lagoas anaeróbias é na ordem de 50 a $60 \%$, tendo assim um DBO considerável, necessitando de tratamento, e o sistema mais utilizado para tratar esse DBO residual são as lagoas de floculação.

As saídas "Consumo e armazenamento de lenha", lenha destinada à geração de energia na caldeira e a "Fumaça proveniente da caldeira" são importantes saídas a se considerar, já que a falta de manutenção periódica da caldeira e dos filtros da chaminé acarretam 
num gasto elevado e desnecessário de lenha, o que é agravado pelo seu armazenamento inadequado, e também uma filtragem deficiente dos gases, proporcionando assim um ar carregado de contaminantes.

Evento semelhante ocorre com a saída "Gases provenientes dos digestores", no qual temos severidade Moderada e ocorrência Alta, o que implica em produto danoso ao meio ambiente e ocorrência diária. Esse impacto é decorrente da falta de filtros, acarretando no lançamento de contaminantes na atmosfera, podendo ser evitado com a instalação de filtros.

Os resíduos que não são gerados diretamente pelo produto em questão, mas que de certa forma estão ligados ao processo, também podem ser um agravante ao meio ambiente, que é o caso das saídas "Embalagens de matérias-primas, insumos, embalagens de papel e plástico" e "Cinzas", quando descartados de maneira irregular podem causar grande dano ao meio ambiente, entretanto atitudes simples podem reverter esse quadro, como é o caso das embalagens, situação em que o adequado a se fazer é a separação e a reciclagem.

\section{CONCLUSÃO}

A utilização do método FMEA na avaliação dos riscos provenientes da atividade de abate suíno e bovino foi uma ferramenta eficaz no diagnóstico dos possíveis impactos e nos impactos efetivamente gerados.

Águas residuárias provenientes da higienização de pisos, equipamentos, carcaças, e da higienização de currais, pocilgas, corredores, caminhões e animais são os fatores que representam os maiores riscos e impactos ambientais gerados pela indústria de abate animal.

A indústria frigorífica representa um grande potencial poluidor sobre os efluentes naturais, pois o sangue resultante do abate, quando não tratado ou utilizado para produção de farinha, é um agente de impacto sobre o ecossistema hídrico, pois eleva os níveis de DBO e Demanda Química de Oxigênio DQO a níveis altíssimos, por se tratar de um excelente meio de cultura para microrganismos.

Ações corretivas e investimentos em pesquisa e mudanças no processo podem implicar na diminuição do impacto ambiental causado e em grande ganho para a unidade frigorífica.

\section{REFERÊNCIAS}

ASSOCIAÇÃO GAÚCHA PARA A QUALIDADE - AGQ. (2006) Curso FMEA: Análise de modo e efeitos de falha em potencial. 3. ed. Novo Hamburgo: AGQ. 48 p.

BRASIL. (1934) Decreto no 24.643, de 10 de julho de 1934. Governo Provisório da República dos Estados Unidos do Brasil. Diário Oficial da União, Rio de Janeiro, RJ, 20 jul. Seção 1, p. 14738.

BRASIL. (1997) Lei no 9.433, de 08 de janeiro 1997. Institui a Política Nacional de Recursos Hídricos. Diário Oficial da União, Brasília, DF, 9 jan. Seção 1, p. 470.

BRASIL. (2000) Lei no 9.984, de 17 de julho de 2000. Institui a Política Nacional de Recursos Hídricos. Diário Oficial da União, Brasília, DF, 18 jul. Seção 1, p. 1

BRASIL. (2001) Resolução no 16, de 8 de maio de 2001. Conselho Nacional de Recursos Hídricos. Diário Oficial da União, Brasília, DF, 14 de maio.

BRASIL. (2011) Resolução no 430, de 13 de maio de 2011. Conselho Nacional do Meio Ambiente. Diário Oficial da União, Brasília, DF, 13 mai. no 092, p. 89

CIKOSKI, A.; ROTTA, M.; BECEGATO, V.; MACHADO, W.C.P.; ONOFRE, S.B. (2008) Caracterização de efluentes gerados no processo agroindustrial: caso da indústria frigorífica. Revista Eletrônica do Curso de Geografia do Campus Jataí - Universidade de Goiás, n. 11, p. 92-102.

DONAIRE, D. (1999) Gestão Ambiental na Empresa. 2. ed. São Paulo: Ed. Atlas. 134 p.
FERROLI, P.C.M.; FIOD NETO, M.; CASAROTTO FILHO, N.; CASTRO, J.E.E. (1998) Emissão zero: uma visão da metodologia ZERI em fábricas de subproduto de origem animal. Produto \& Produção, v. 2, n. 3, p. 66-74.

HELMAN, H. \& ANDERY, P.R.P. (1995) Análise de falhas (Aplicação dos métodos de FMEA e FTA). Belo Horizonte: Fundação Christiano Ottoni - Escola de Engenharia da UFMG. 174 p.

MOURA, L.A.A. (2000) Qualidade e Gestão Ambiental. 2. ed. São Paulo: Juarez de Oliveira.

NOGUEIRA, A.C.; PERES, A.P.; CARVALHO, E.M. (2011) Avaliação do Risco Ambiental utilizando FMEA em um laticínio na região de Lavras-MG. Revista Produção Online, v. 11, p. 194-209.

OZILGEN, S. (2O12) Failure Mode and Effect Analysis (FMEA) for confectionery manufacturing in developing countries: Turkish delight production as a case study. Ciência e Tecnologia de Alimentos, v. 32, n. 3, p. 505-514.

PALADY, P. (1997) FMEA: Análise dos Modos de Falha e Efeitos: prevendo e prevenindo problemas antes que ocorram. São Paulo: IMAM.

PELISSER, M. \& SOARES, H. (2001) Remoção microbiológica de nitrogênio de águas residuárias da indústria frigorífica. 2001. 208 fl. Dissertação (Mestrado em Engenharia Química), Centro Tecnológico da Universidade Federal de Santa Catarina.

PUENTE, J.; PINO, R.; PRIORE, P.; FOUENTE, D. (2002), Um sistema de apoio à decisão para a aplicação de modos de falha e análise de efeitos. Jornal Internacional de Qualidade e Gestão de Confiabilidade, v. 19, n. 2, p. 378-397. 
SCARASSATI, D.; CARVALHO, R.F.; DELGADO, V.L.; CONEGLIAN, C.M.R; BRITO, N.N.; TONSO, S.; SOBRINHO, G.D.; PELEGRINI, R. (2003) Tratamento de Efluentes de Matadouros e Frigoríficos. In: III Fórum de Estudos Contábeis. São Paulo: Faculdades Integradas Claretianas.

SENA, R.F. (2005) Avaliação da biomassa obtida pela otimização da flotação do efluente da indústria de carnes para geração de energia. 2005. 79f. Dissertação (Mestrado em Engenharia Química) Universidade Federal de Santa Catarina, Florianópolis.
STAMATIS, D.H. (2003) Failure Mode and Effect Analysis: FMEA from theory to execution. 2. ed. Milwaukee: Quality Press.

THEBALDI, M.S.; SANDRI, D.; FELISBERTO, A.B.; ROCHA, M.S.; NETO, S.A. (2011) Qualidade da água de um córrego sob influência de efluente tratado de abate bovino. Revista Brasileira de Engenharia Agrícola e Ambiental, v. 15, n. 3, p. 302-309.

ZAMBRANO, T.F. \& MARTINS, M.F. (2007) Utilização do Método FMEA para avaliação do risco ambiental. Gestão \& Produção, v. 14, n. 2, p. 295-309. 